\title{
Geometric Development of Point Absorber Wave Energy Conventer
}

\author{
Heri Saptono Warpindyasmoro ${ }^{1, *}$, and Kartika Gunadi $^{2}$ \\ ${ }^{1}$ Electrical Engineering Department, Petra Christian University, Jl. Siwalankerto 121-131, Surabaya, 60234, Indonesia \\ ${ }^{2}$ Informatics Engineering Department, Petra Christian University, Jl. Siwalankerto 121-131, Surabaya, 60234, Indonesia
}

\begin{abstract}
This paper describes how to design the shape of a floating object that will be used as a point absorber on wave energy converster. The buoyant shape to be analyzed is a tube has a flat top plane with varying bottom plane, i.e cylinder, hemisphare and cone. The analysis was conducted on the diameter of the object and the influence of the ocean wave period on the area where the apparatus was later applied in the southern coast of East Java. Using Moses's software, it is found that the diameter of the body is proportional to the period in which the maximum of Response Amplitude Operator floating object. The object with a flat bottom field (cylinder) produces the largest period, which is $10 \mathrm{~s}$, followed by a curve shape of a hemisphere with a period of $9 \mathrm{~s}$ and last with a cone shape cone with a period of at least $8 \mathrm{~s}$. This shows that the curvature of the bottom of the buoyancy can be adjusted according to the wave period to obtain maximum Response Amplitude Operator.
\end{abstract}

Key words: Point absorber, wave energy conventer.

\section{Introduction}

The need for electrical energy always increase along with economic growth and population growth. Energy demand in Indonesia has increased by $6 \%$ per year. In 2025 it takes an additional energy of $180 \%$ of the present. This means that energy demand will increase from 3000000 BOEPD (Barrels Of Oil Equivalent Per Day) to 8300000 BOEPD. Of the current electrical energy needs obtained from new renewable energy sources $5.7 \%$. Indonesia has an ocean of $5800000 \mathrm{~km}^{2}$ or $70 \%$ of the total territory of Indonesia, this is a huge potential as a source of renewable energy from ocean energy. The government has targeted to start building a ocean energy power plant with a capacity of $3 \mathrm{MW}$ of the type of ocean currents, and $10 \mathrm{MW}$ of the type of ocean heat. The potential of ocean energy in Indonesia is still not utilized, so there needs to be a study related to the potential of ocean energy in Indonesia. Ocean energy has been the concern of researchers, both in Indonesia and in other countries. Studies of wind, ocean currents and waves in the Sunda Strait as an alternative energy have been made [1]. From this research, it is found that in Sunda Strait have wave energy potential with maximum wave height $3.2 \mathrm{~m}$ with period $17 \mathrm{~s}$ with electric energy potential 92 $\mathrm{kW} \mathrm{m}{ }^{-1}$. Ocean waves caused by wind. The relationship between the wind and the waves, especially the wave period on the south coast of West Java [2]. In this study it is found that wind and wave patterns vary greatly according to seasonal pattern (quarter). Tide modeling has been done in the Alas Strait (between Lombok Island and Sumbawa), the estimated energy obtained in one year is $330 \mathrm{GWh}[3]$.

The potential of ocean energy is quite large, therefore it is necessary equipment that can convert the ocean energy into electrical energy. To convert wave energy into electrical energy required a floating object (point absorber) that can move vertically in accordance with the waveform that comes to it. Before the shape of the floating object is implemented, a simulation is needed to estimate the energy produced. One of the wave energy conversion simulators is WEC-Sim developed by The National Renewable Energy Laboratory (NREL) and Sandia National Laboratories (SNL). This simulator has successfully simulated several forms such as flap [4], applying a buoyancy force and non-linear excitation forces [5], and arbitrary geometric [6]. Several studies have been conducted to study the effect of the shape of buoyancy on the energy produced [7-10]. In this papaer presented the results of research related to the influence of the form of objects with variations in diameter to produce maximum energy. 


\section{Mass-spring-damper system linear model}

In general, floating objects move in six degrees of freedom. That is, the translational motion in the direction of the $\mathrm{x}, \mathrm{y}$, and $\mathrm{z}$ axes, each of which is called: surge, swey and heave, and rotational motion against the $\mathrm{x}, \mathrm{y}$ and $\mathrm{z}$ axes respectively are called roll, pitch and yaw, as seen in Figure 1.

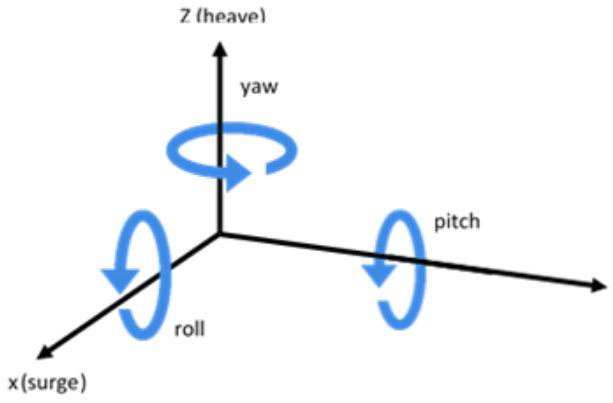

Fig. 1. Motion of buoyancy in 6 degrees freedom.

In the subsequent discussion of motion floating objects only reviewed in 1 dimension only the motion towards the $\mathrm{z}$ axis (heave). This is due to the motion of a buoyancy object connected with Power Take Off (PTO) equipment in the form of a linear generaor where the translator moves toward the $\mathrm{z}$ axis as shown in Figure 2.

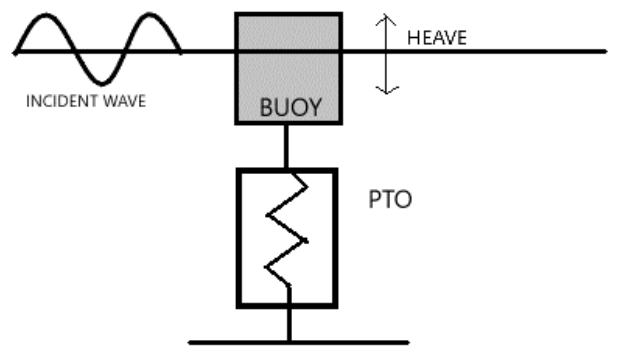

Fig. 2. Linear Mass-Spring-Damped model.

\subsection{Forces on floating objects}

One method for analyzing float motion is the Linear Model Mass-Spring-Damper System [11]. The forces in floating objects are:

\subsubsection{Floating force (FA)}

The floating force is an Archimedes force equal to the weight of the liquid removed by the floating object. This buoyant force will be a restoring force that will bring objects back to a point of equilibrium. This buoyancy force or restoring force is:

Where:

$$
F_{A}=-C_{A} z
$$

$\mathrm{C}_{\mathrm{A}} \quad$ : restoring constant $\left(\mathrm{N} \mathrm{m}^{-1}\right), \mathrm{C}_{\mathrm{A}}=\rho g \mathrm{~A}_{\mathrm{wl}}$

$\rho \quad$ : density of ocean water

g : : the acceleration of gravity

$\mathrm{A}_{\mathrm{wl}} \quad$ : The cross section of the floating object on the surface of the water.

$\mathrm{z} \quad$ : displacement toward $\mathrm{z}$ axis

A negative sign to indicate that the $\mathrm{F}_{\mathrm{A}}$ direction is always opposite to the direction of the object motion.

\subsubsection{Mass addition force (Fm)}

At the moment the floating object oscillates there will be an increase in the water mass as it exits and enters the water surface. This water mass will increase the mass of a floating object as $\mathrm{m}_{\mathrm{a}}$. So will contribute force for: 


$$
F_{m}=m_{a} \ddot{z}
$$

Where:

$\mathrm{m}_{\mathrm{a}} \quad$ : addition of mass $(\mathrm{kg})$

$\mathrm{z} \quad$ : acceleration of vertical motion of buoyancy $\left(\mathrm{m} \mathrm{dt}^{-2}\right)$

\subsubsection{Damping force}

Damping force as a result when the floating object is moving against the water. Due to this damping force there will be a force radiated out by the system. Therefore this damping force is also called the radiation force (Frad). Thus the magnitude of this radiation force is:

$$
F_{\text {rad }}=-b z
$$

Where:

$\mathrm{b}=$ damping constant $\left(\mathrm{kg} \mathrm{dt}^{-1}\right)$

$\mathrm{z}=$ vertical velocity of the object $\left(\mathrm{m} \mathrm{dt}^{-1}\right)$

\subsubsection{PTO force}

If the floating object is connected to the PTO equipment, then there will be energy released/transferred to be converted into electrical energy. This PTO force is also viewed as a damping force, so the magnitude of the PTO force is:

$$
F_{P T O}=-\beta \tilde{z}
$$

Where:

$\beta=$ PTO damping constant,

$\beta=\sqrt{b\left(\omega_{p}\right)^{2}+\frac{1}{\omega_{p}^{2}}\left(-\left(m-m_{a}\left(\omega_{p}\right)\right) \omega_{p}^{2}+C_{A}+k_{p}\right)^{2}}$

$\mathrm{Z}=$ vertical velocity of the object $(\mathrm{m} / \mathrm{dt})$

\subsubsection{Excitation force}

Excitation Force is the influence of waves that result in pressure changes in the fluid on the surface of floating objects. This excitation force is obtained from a non-hydrostatic state, because the hydrostatic is said to be a buoyant force or restoring force. This excitation force is Froude-Krylov force and Diffraction force.

\subsubsection{Spring force.}

This spring force is a mechanical force connecting floating objects and PTO equipment. This force is equivalent to a restoring force called Fp.

$$
F_{p}=k_{p} z
$$

Where:

$\mathrm{kp}=$ the spring constant

$k_{p}=\omega_{p}\left[m+m a\left(w_{p}\right)\right]-C_{A}$

$\mathrm{z}=$ position of floating objects.

From Newton's law, it is related to the forces acting on a floating object are obtained

$$
F=m \bar{z}
$$

$$
\begin{aligned}
F_{A}+F_{m}+F_{\text {rad }}+F_{P T O}+F_{E k s}+F_{\mathrm{p}} & =m \ddot{z} \\
-C_{A} z+m_{a} z \ddot{z}-b \tilde{z}-\beta \tilde{z}+F e k s-k_{g} z & =m \ddot{z} \\
(m+m a) \tilde{z}+(b+\beta) \tilde{z}+\left(C_{A}+k\right) & =f_{e h s}
\end{aligned}
$$

\section{Result and discussion}

\subsection{Determination of geometric point absorber}

This research begins by determining the shape of a floating object. The selected floating object is an object with a top surface in the form of a circular plane with diameter $\mathrm{D}$, whereas the lower plane has different shape: cylinder, hemisphare and cone with length respectively is $\mathrm{L}=1,5 \mathrm{D}$. The shape of the object as in Figure 3. 


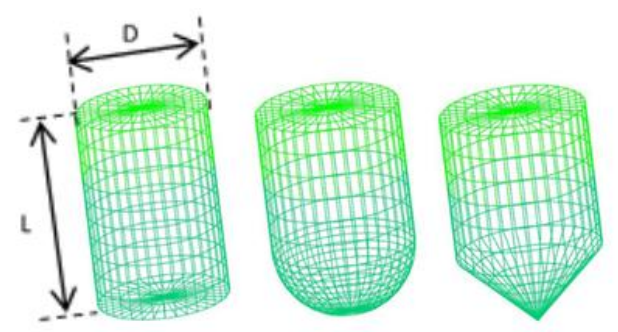

Fig. 3. The shape and dimensions of objects.

\subsection{Effect of diameter floating object on response amplitude operation (RAO)}

Using the MOSES simulation software, the diameter of a floating object varies with $\mathrm{D}=6 \mathrm{~m}, 9 \mathrm{~m}, 12 \mathrm{~m}, 15 \mathrm{~m}$ and $18 \mathrm{~m}$ with floating material length $\mathrm{L}=1.5 \mathrm{D}$. The simulation results can be seen in Figure 4 for the cylinder, Figure 5 for the hemisphere and Figure 6 for cone.

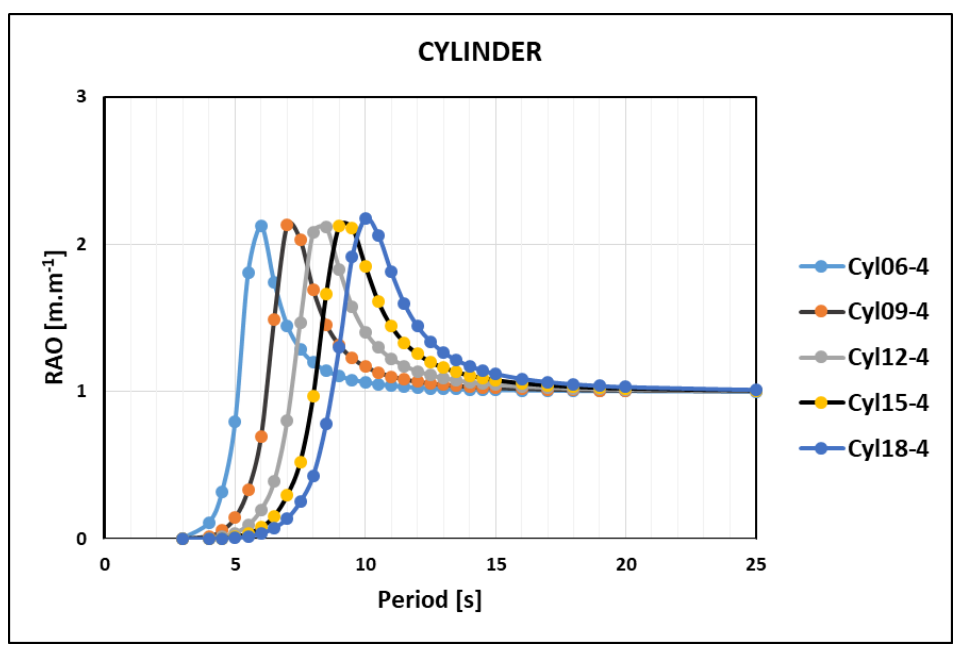

Fig. 4. RAO for cylinder with variation of diameter cylinder.

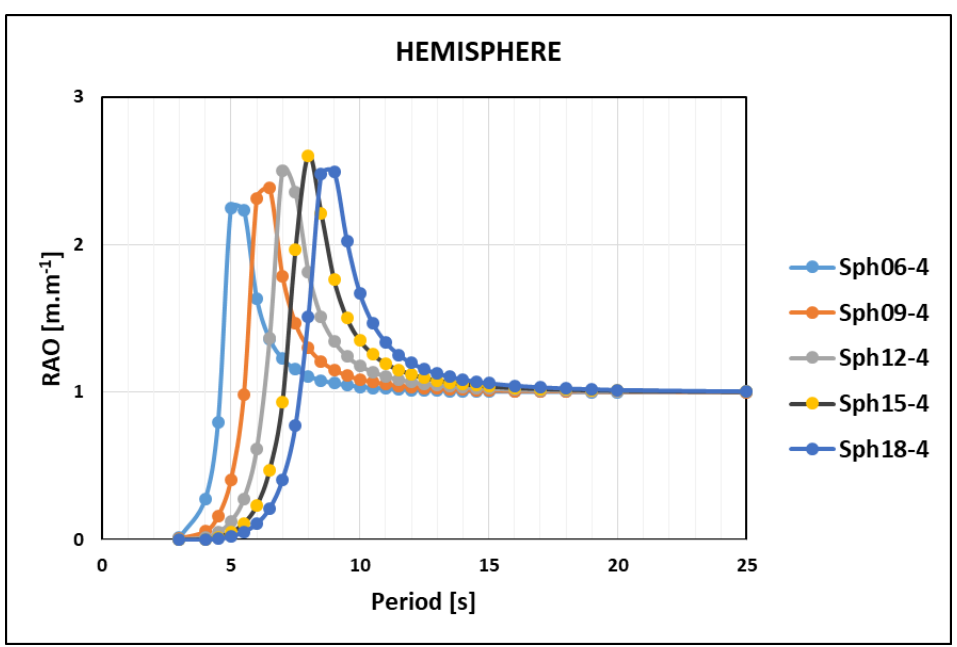


Fig. 5. RAO for a hemisphere with variations of diameter hemisphere.

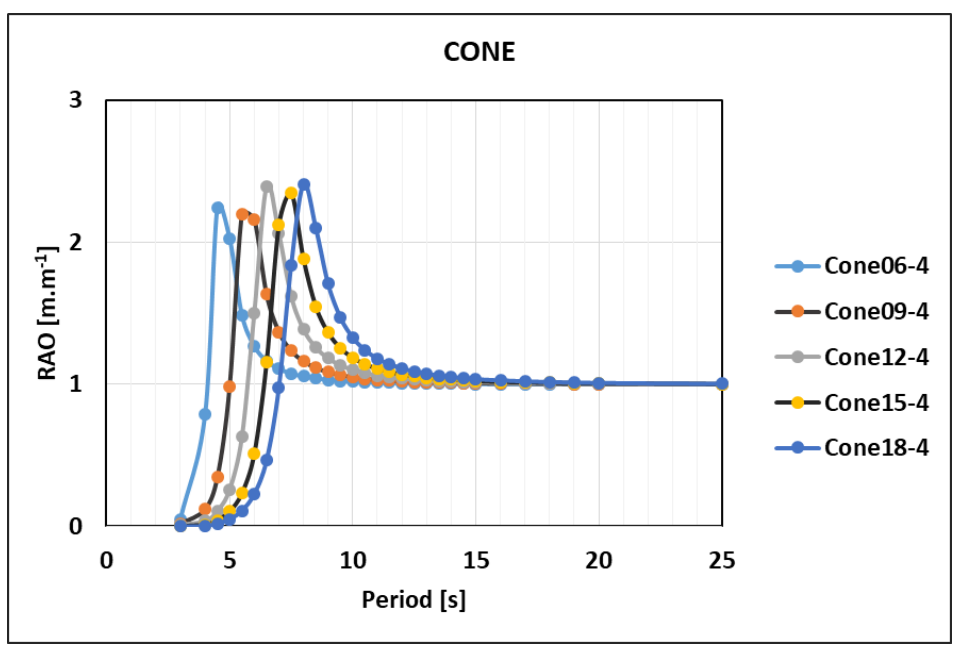

Fig. 6. RAO for cones with variations of diameter cone.

From the RAO simulation results in Figure 4 to Figure 6, the diameter of the object is proportional with the period at which the maximum RAO occurs. To determine the effect of the shape of the object on the period in which the maximum RAO is generated, it is simulated for all three objects with the same diameter $(\mathrm{D}=18 \mathrm{~m})$ and the same draft $(\mathrm{T}=4 \mathrm{~m})$. The simulation results are shown in Figure 7.

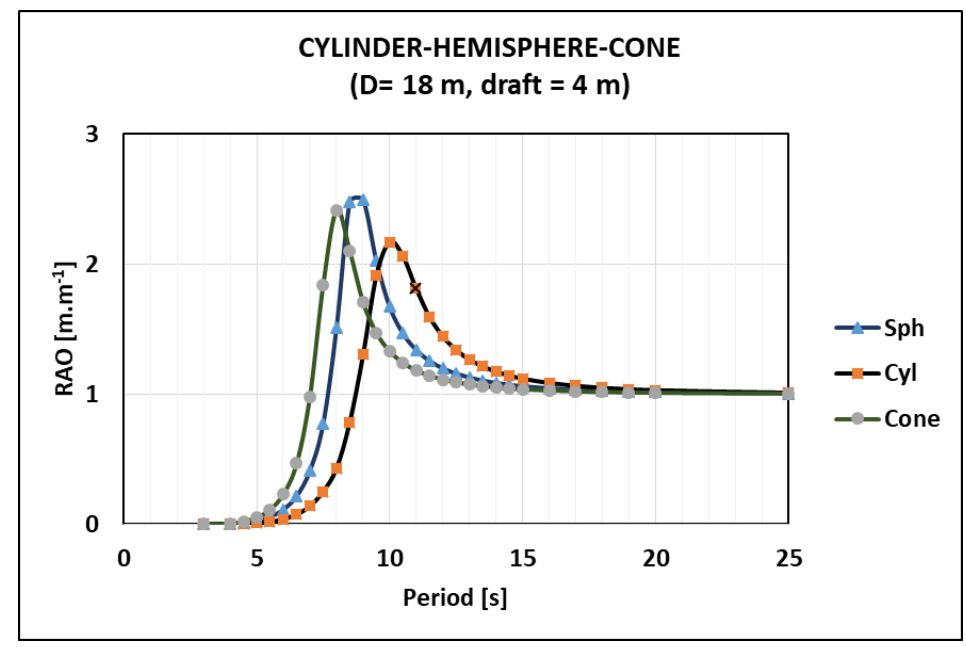

Fig. 7. Comparison of maximum RAO on cylinder, hemisphere and cone forms.

From Figure 7 it appears that the period for generating maximum RAO is different for each object. The object with a flat bottom field (cylinder) produces the largest period, which is $10 \mathrm{~s}$, followed by a curve shape of a hemisphere with a period of $9 \mathrm{~s}$ and last with a cone shape cone with a period of at least $8 \mathrm{~s}$. This shows that the curvature of the bottom of the buoyancy can be adjusted according to the wave period so as to obtain maximum RAO.

\section{Conclusions}

From the simulation results of the three forms of floating objects obtained that the greater the diameter of the object will produce maximum RAO in the larger period. The shape of the bottom of the floating object affects the period to produce the maximum RAO. The period will be smaller when the bottom shape is changed from the flat (cylinder), curve (hemisphere) and tilt (cone). 
This research is funded by a grant from the Ministry of Research, Technology and Higher Education of the Republic of Indonesia

\section{References}

[1] R. Sandro, Arnudin, A. Tussadiah, R.M. Utamy, N. Pridina, L.N. Afifah. Energy Procedia 47:242-249 (2014). https://www.sciencedirect.com/science/article/pii/S1876610214002367

[2] N.P. Purba. Jurnal Akuatikan 5(1):8-15 (2014). [in Bahasa Indonesia]. http://jurnal.unpad.ac.id/akuatika/article/view/3699

[3] L.S. Blunden, A.S. Bahaj, N.S. Aziz. Renewable Energy 49(January):137-142 (2013). https://www.sciencedirect.com/science/article/pii/S0960148112000572

[4] Y.-H. Yu, Y. Li, K. Hallett, C. Hotimsky. Design and analysis for a floating oscillating surge wave energy converter. The $33^{\text {rd }}$ International Conference on Ocean, Offshore and Arctic Engineering. pp. 1-10 (San Francisco, CA, 2014). https://www.nrel.gov/docs/fy14osti/61283.pdf

[5] K. Ruehl, C. Michelen, S. Kanner, M. Lawson, Y. H. Yu. Preliminary Verification and Validation of WEC-Sim, an Open-Source Wave Energy Converter Design Tool. The $33^{\text {rd }}$ International Conference on Ocean, Offshore and Arctic Engineering. pp. 1-8 (San Francisco, California, 2014). https://www.nrel.gov/docs/fy14osti/61531.pdf

[6] K. Ruehl, R. Paasch, T. K. A. Brekken, and B. Bosma. Wave energy converter design tool for point absorbers with arbitrary device geometry. The Twenty-third International Offshore and Polar Engineering Conference. pp. 538545 (Anchorage, Alaska, 2013). https://www.onepetro.org/conference-paper/ISOPE-I-13-193

[7] P.J.B.F.N. Beirão, C.M.S.P. Malça. International Journal of Energy and Environmental Engineering, 5(91):1-11 (2014). https://link.springer.com/article/10.1007/s40095-014-0091-7

[8] J. Kim, H. Kweon, W. Jeong, I. Cho, and H. Cho. Int. J. Nav. Archit. Ocean Eng., 7(4):739-749 (2015). https://www.sciencedirect.com/science/article/pii/S2092678216300450

[9] H. Gao. B. L i. Polish Maritime Research, 22(1):106-111 (2015). https://www.degruyter.com/view/j/pomr.2015.22.issue-s1/pomr-2015-0041/pomr-2015-0041.xml

[10] J. Orszaghova, A. Rafiee, H. Wolgamot, S. Draper, and P.H. Taylor. Experimental study of extreme responses of a point absorber wave energy converter. 20th Australasian Fluid Mechanics Conference. pp. 2-5 (Perth, Australia, 2016). http://people.eng.unimelb.edu.au/imarusic/proceedings/20/753\%20Paper.pdf

[11]F. Kalofotias. Study for the hull shape of a wave energy converter-point absorber. [Thesis] Master of Science, Water Enggineering and Management, University of Twente (2016). pp. 16-19. https://www.utwente.nl/en/et/wem/education/msc-thesis/2016/kalofotias.pdf 